\title{
Severe Acute Hemolytic Transfusion Reaction Treated with Ruxolitinib and Plasma Exchange
}

\author{
Burak Deveci $^{a}$ Rabin Saba ${ }^{b}$ Husnu Altunayc ${ }^{c}$ Tayfur Toptas ${ }^{d}$

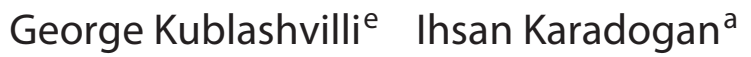 \\ ${ }^{a}$ Hematology and Stem Cell Transplantation Unit, Medstar Antalya Hospital, Antalya, Turkey; ${ }^{b}$ Infectious Disease Unit, \\ Medstar Antalya Hospital, Antalya, Turkey; ' Blood Bank and Transfusion Center, Medstar Antalya Hospital, Antalya, \\ Turkey; ${ }^{\mathrm{d} D e p a r t m e n t}$ of Hematology, Marmara Universitesi Tip Fakultesi, Istanbul, Turkey; ${ }^{\mathrm{e}}$ Hematology and Stem Cell \\ Unit, Medstar Antalya Hospital, Antalya, Turkey
}

\section{Keywords}

Acute hemolytic transfusion reaction - Cytokines .

Hemovigilance $\cdot$ Ruxolitinib

\begin{abstract}
Introduction: Acute hemolytic transfusion reaction is a rare but extremely mortal condition. Even small quantities of ABO-incompatible erythrocytes, as much as $50 \mathrm{~mL}$, can lead to fatality. Since there is no successful standard therapy, preventive measures are very important. In this case report, we presented a 29-year-old woman who was transfused with 2 units of $A B$ Rh-positive instead of 0 Rh-positive red blood cells following a cesarean section. As far as we know, this is the first patient in the literature for whom ruxolitinib was used as a part of therapy. Case Report: The patient was referred to our center $22 \mathrm{~h}$ after the ABO-mismatched transfusion. On admission, she had severe hemolysis, acute renal failure, and disseminated intravascular coagulation. Massive plasma exchange, hemodialysis, and pulse steroid therapy were commenced. The patient was refractory to first-line therapies. She was intubated on day 2 due to hypoxia, respiratory failure and changes in consciousness. Ruxolitinib, $2 \times$ $10 \mathrm{mg} /$ day, was started on day 3. The patient's clinical status improved on day 6. Ruxolitinib was withdrawn on day 15 , and the patient was discharged without any complications or sequels on day 26. Conclusion: Ruxolitinib may be lifesaving in patients with $\mathrm{ABO}$-incompatible transfusion reaction which follows a severe and catastrophic course.
\end{abstract}

(c) 2021 S. Karger AG, Basel

\section{Case Report}

Case Presentation

A 29-year-old female with type 0 Rh-positive blood group was transfused with 2 units of type AB Rh-positive RBCs following a transfusion. She was anuric. She had severe hemolysis, respiratory insufficiency, acute renal failure, and disseminated intravascular coagulation (DIC). Her initial laboratory results were as follows: hemoglobin: $6.9 \mathrm{~g} / \mathrm{dL}$, WBC: $17,940 / \mu \mathrm{L}, \mathrm{PLT}$ : $116,000 / \mu \mathrm{L}$, reticu, $10.1 \%$, total/direct bilirubin: $2.7 / 0.3 \mathrm{mg} / \mathrm{dL}$, respectively, prothrombin time: $17.4 \mathrm{~s}$ (upper limit of normal [ULN]: $15.5 \mathrm{~s}$ ), activated partial thromboplastin time: $37.4 \mathrm{~s}$ (ULN: $36 \mathrm{~s}$ ), INR: (AHTR) due to ABO-incompatible red blood cell (RBC) transfusion is a rare but highly mortal reaction [1]. Even small quantities of $\mathrm{ABO}$-incompatible erythrocytes, as much as $50 \mathrm{~mL}$, can lead to death. Since there is no successfully standard therapy, preventive measures are very important. Generation of massive antigen-antibody complexes is crucial in the pathogenesis of AHTR. These associated with multiorgan failure and death [2-5]. Here, present an immune-competent patient, who received ed with massive plasma exchange (PEX) and ruxolitinib therapy.

deveci.burak@gmail.com 
Table 1. Overview of the parameters used

\begin{tabular}{|c|c|c|c|c|c|c|c|c|c|}
\hline Parameter & Day 1 & Day 2 & Day 3 & Day 4 & Day 6 & Day 7 & Day 8 & Day 15 & Day 27 \\
\hline Hemoglobin, g/dL & 6.9 & 8.5 & 8.3 & 10.7 & 10.4 & 10.3 & 9.5 & 8.9 & 10.8 \\
\hline Hematocrit, \% & 20.9 & 24.2 & 23.9 & 32 & 31.1 & 30.9 & 28.4 & 27.1 & 32.2 \\
\hline Reticulocytes, \% & 10.3 & 11.8 & 11.2 & 10 & 7.3 & 7.6 & 6 & 2.01 & 1.07 \\
\hline $\mathrm{WBC}, 10^{3} / \mu \mathrm{L}$ & 17,900 & 17,400 & 19,900 & 17,700 & 17,300 & 15,500 & 18,100 & 10,000 & 5,900 \\
\hline Platelets, $10^{3} / \mu \mathrm{L}$ & 138 & 133 & 143 & 108 & 148 & 184 & 226 & 380 & 373 \\
\hline Prothrombin time, s & 17.4 & 13.3 & 14 & 13.2 & 14.2 & 14.7 & 16.8 & 14 & 12.1 \\
\hline INR & 1.33 & 1.37 & 1.54 & 1.2 & 1.07 & 1.11 & 1.28 & 1.06 & 0.91 \\
\hline D-dimer, $\mu \mathrm{g} / \mathrm{mL}$ & $>3,000$ & $>3,000$ & $>3,000$ & 2,290 & 1,020 & 800 & 850 & 150 & Not tested \\
\hline Fibrinogen, mg/dL & $<50$ & 52 & 54 & 102 & 208 & Not tested & Not tested & Not tested & Not tested \\
\hline Anti-A titer & $1 / 64++, 1 / 32+++$ & Not tested & Not tested & Not tested & Not tested & Not tested & Not tested & Not tested & Not tested \\
\hline Anti-B titer & $1 / 64+++$ & Not tested & Not tested & Not tested & Not tested & Not tested & Not tested & Not tested & Not tested \\
\hline Serum creatinine & 2.17 & 2.72 & 3.89 & 3.52 & 4.84 & 5.82 & 4.64 & 2.55 & \\
\hline Blood urea nitrogen & 54 & 75 & 92 & 86 & 103 & 152 & 88 & 32 & 51 \\
\hline Bilirubin (total) & 2.73 & 2.77 & 1.88 & 1.02 & 0.35 & 0.32 & 0.3 & 0.29 & 0.19 \\
\hline Bilirubin (direct) & 0.67 & 0.29 & 0.26 & 0.1 & 0.1 & 0.15 & 0.14 & 0.11 & 0.9 \\
\hline $\mathrm{LDH}$ & 522 & 513 & 425 & 401 & 385 & 337 & 315 & 526 & 162 \\
\hline Potassium & 5.4 & 5.8 & 4 & 3.8 & 4.1 & 4.3 & 3.4 & 4 & 4.8 \\
\hline Blood gas pH (arterial) & 7.45 & 7.52 & 7.59 & & 7.46 & 7.42 & 7.44 & 7.42 & 7.4 \\
\hline $\mathrm{HCO}$ & 25.7 & 32.2 & 32 & & 27.9 & & & & \\
\hline Direct antiglobulin test & $\operatorname{IgG}+++C 3 d+++$ & $\begin{array}{l}\mathrm{IgG}+++ \\
\mathrm{C} 3 \mathrm{~d}+++\end{array}$ & Not tested & Not tested & $\begin{array}{l}\mathrm{IgG}++ \\
\mathrm{C} 3 \mathrm{~d}+\end{array}$ & Not tested & Not tested & Negative & Negative \\
\hline ABO grouping (forward) & Mixed population & Not tested & Not tested & 0 Rh-positive & Not tested & Not tested & Not tested & Not tested & 0 Rh-positive \\
\hline
\end{tabular}

1.33. Fibrinogen was $<50 \mathrm{mg} / \mathrm{dL}$, D-Dimer was $>3,000 \mu \mathrm{g} / \mathrm{L}$ (ULN: $500 \mu \mathrm{g} / \mathrm{L})$. Arterial blood gas analysis showed pH: 7.29, sO2: 89\%, pO2: $27.2 \mathrm{~mm} \mathrm{Hg}$, pCO2: $35.2 \mathrm{~mm} \mathrm{Hg}$, cHCO3: $9.5 \mathrm{mmol} / \mathrm{L}$ (Table 1). On admission, pulse steroid (1,000 mg/day), plasma exchange (PEX, 2 volumes per procedure, twice a day, with AB Rhpositive fresh frozen plasma) and hemodialysis were started. She received a total of 8 units of erythrocyte suspensions in the first 4 days of admission. Despite those supportive care and plasma exchanges, her condition deteriorated and she was intubated due to respiratory failure and changes in consciousness on day 2. Ruxolitinib, $2 \times 10 \mathrm{mg} /$ oral, was started and continued via nasogastric tube after intubation on day 3. On day 6 , the patient was extubated. She was transferred from the intensive care unit to the hematology ward on day 7. Urinary excretion started, hemodialysis was withdrawn. Hemodialysis was performed on the first week of her admission. PEX was performed twice daily first, then continued with one procedure per day and it was stopped on day 10 . Ruxolitinib was ceased on day 15 . The patient was discharged with normal blood counts and renal functions without any sequel or complications on day 26.

\section{Discussion}

$\mathrm{ABO}$-incompatible $\mathrm{RBC}$ transfusions are important causes of mortalities in clinical practice. Generally, AHTR occurs very rapidly and its clinical findings become overt within seconds to minutes. Most of the survivors are those who are transfused with only small amounts of RBCs, old and/or immunocompromised patients. There is no standard successful therapy for ABO-incompatible $\mathrm{RBC}$ transfusion. Most of the therapies rely on supportive measures such as stabilization of hemodynamic changes, hemodialysis, and transfusion of blood components for DIC. Excessive cytokine release is one of the main pathogenetic events that lead to multi-organ failure in these patients $[5,6]$. Steroids and PEX can eliminate cytokine release but is generally insufficient in most patients [3]. These therapeutic approaches are more effective in early periods of AHTR; however, in our case, the patient was referred to our hospital $22 \mathrm{~h}$ after the transfusion. PEX is effective in removing anti- $\mathrm{A}$ and anti-B antibodies, and cytokines as well. But the formation of antigen-antibody complexes leads to complement activation. Complement-mediated multi-organ failure and complications may not be ameliorated by PEX. Therefore, additional supportive therapies are required.

Ruxolitinib is a potent and immediate inhibitor of many cytokines. It inhibits cytokines by blocking the JAK-STAT pathway. JAKs constitute a kinase family which has 4 members. Among those, JAK-1 is associated with cytokine release, especially tumor necrosis factor alpha (TNF- $\alpha$ ). Ruxolitinib suppresses dendritic cells, natural killer cells and $\mathrm{T}$ cells by blocking the JAK-STAT pathway. By this way, it inhibits release of many cytokines, especially TNF- $\alpha$ [7]. In AHTR, the role of cytokines such as, TNF- $\alpha$, interleukin- $1 \beta$, interleukin- 6 , and chemokines interleukin-8, monocyte chemoattractant protein-1 and interleukin-1 receptor antagonist has previously been mentioned [8]. In addition, we know that among these cytokines, TNF- $\alpha$ is one of the key mediators 
in AHTR-induced DIC [9]. Our patient had severe DIC and acute renal failure; those were the consequences of massive endothelial damage and hemolysis. Therefore, we may have 2 therapeutic targets: complement system and cytokine blockage.

The potent complement inhibitor eculizumab has been used to treat AHTR so far. Weinstock et al. [10] have published a case report of a patient with paroxysmal nocturnal hemoglobinuria who experienced AHTR and was successfully treated with eculizumab. Eculizumab is a monoclonal antibody that blocks complement 5 (C5) [11]. It inhibits formation of membrane attack complex. In our case, eculizumab was not available at admission. So we decided to block the cytokine release by ruxolitinib. Our patient was young and immune-competent and transfused with large amounts of $\mathrm{ABO}$-incompatible RBCs. Considering those factors, she had a high risk of death. Supportive measures, including plasma exchange, were not sufficient to block the catastrophic course of the disease. However, treatment with ruxolitinib dramatically changed the rapidly progressive multiorgan failure in our patient.

Ruxolitinib may be life-saving in patients with $\mathrm{ABO}$ incompatible transfusion reaction which follows a severe and catastrophic course.

\section{Statement of Ethics}

All authors declare that the research was conducted ethically in accordance with the World Medical Association Declaration of Helsinki. Informed consent has been obtained from the patient for publication. The Memorial Hospitals Group Ethics Committee has approved that case report.

\section{Conflict of Interest Statement}

All authors confirm that there are no conflicts of interest to report.

\section{Funding Sources}

No funding was received.

\section{Author Contributions}

B.D. and I.K. planned this work and participated in clinical follow-up, interpretation of data, manuscript preparation, completion, and final approval of the manuscript. R.S. and H.A. performed all laboratory tests and collected data for publication and approved the final manuscript. G.K. and T.T. participated in data interpretation, manuscript preparation, completion, and final approval of the manuscript.

\section{References}

1 Janatpour KA, Kalmin ND, Jensen HM, Holland PV. Clinical outcomes of ABO-incompatible RBC transfusions. Am J Clin Pathol. 2008 Feb;129(2):276-81.

2 Harvey AR, Basavaraju SV, Chung KW, Kuehnert MJ. Transfusion-related adverse reactions reported to the National Healthcare Safety Network Hemovigilance Module, United States, 2010 to 2012. Transfusion. 2015 Apr;55(4):709-18.

3 Namikawa A, Shibuya Y, Ouchi H, Takahashi $\mathrm{H}$, Furuto Y. A case of ABO-incompatible blood transfusion treated by plasma exchange therapy and continuous hemodiafiltration. CEN Case Rep. 2018 May;7(1):114-20.
4 Moussly S, Kropf J, Sarwari N, Sarriera J, Carlan S, Madruga M. Successful use of adjunctive red blood cell exchange therapy for treatment of an acute hemolytic reaction after ABO-incompatible red blood cell transfusion. J Hematol (Brossard). 2019 Sep;8(3):141-3.

5 Davenport RD, Strieter RM, Kunkel SL. Red cell ABO incompatibility and production of tumour necrosis factor-alpha. Br J Haematol. 1991 Aug;78(4):540-4.

6 Davenport RD, Strieter RM, Standiford TJ, Kunkel SL. Interleukin-8 production in red blood cell incompatibility. Blood. $1990 \mathrm{Dec}$; 76(12):2439-42.

7 Elli EM, Baratè C, Mendicino F, Palandri F, Palumbo GA. Mechanisms underlying the anti-inflammatory and immunosuppressive activity of ruxolitinib. Front Oncol. 2019 Nov; 9:1186.
8 Davenport RD. The role of cytokines in hemolytic transfusion reactions. Immunol Invest. 1995 Jan-Feb;24(1-2):319-31.

9 Davenport RD, Polak TJ, Kunkel SL. White cell-associated procoagulant activity induced by ABO incompatibility. Transfusion. 1994 Nov-Dec;34(11):943-9.

10 Weinstock C, Möhle R, Dorn C, Weisel K, Höchsmann B, Schrezenmeier H, et al. Successful use of eculizumab for treatment of an acute hemolytic reaction after ABO-incompatible red blood cell transfusion. Transfusion. 2015 Mar;55(3):605-10.

11 Hillmen P, Young NS, Schubert J, Brodsky RA, Socié G, Muus P, et al. The complement inhibitor eculizumab in paroxysmal nocturnal hemoglobinuria. N Engl J Med. 2006 Sep; 355(12):1233-43 